\title{
Malnutrition-Sarcopenia Syndrome: Is This the Future of Nutrition Screening and Assessment for Older Adults?
}

\author{
Maurits F. J. Vandewoude, ${ }^{1}$ Carolyn J. Alish, ${ }^{2}$ Abby C. Sauer, ${ }^{2}$ and Refaat A. Hegazi ${ }^{2}$ \\ ${ }^{1}$ Department of Geriatrics, ZNA St. Elisabeth Leopoldstraat 26, University of Antwerp, 2000 Antwerp, Belgium \\ ${ }^{2}$ Scientific and Medical Affairs, Abbott Nutrition, Abbott Laboratories, 3300 Stelzer Road, Columbus, OH 43219, USA
}

Correspondence should be addressed to Maurits F. J. Vandewoude, maurits.vandewoude@zna.be

Received 2 April 2012; Accepted 11 July 2012

Academic Editor: Astrid E. Fletcher

Copyright (C) 2012 Maurits F. J. Vandewoude et al. This is an open access article distributed under the Creative Commons Attribution License, which permits unrestricted use, distribution, and reproduction in any medium, provided the original work is properly cited.

\begin{abstract}
Malnutrition is common across varying patient populations, particularly older adults, and sarcopenia prevalence increases with advancing age. Both malnutrition and sarcopenia are associated with substantial adverse outcomes affecting both the patient and the healthcare system, including increased morbidity, mortality, rehospitalization rates, and healthcare costs. Healthcare practitioners may assess patients for either malnutrition or sarcopenia; however, many patients clinically present with both conditions, resulting in the syndrome, Malnutrition-Sarcopenia Syndrome, which is the clinical presentation of both malnutrition and accelerated age-associated loss of lean body mass, strength, and/or functionality. Clinicians are urged to screen, assess, and treat these conditions currently so as to adequately address the full spectrum of patients' nutritional issues. By examining aspects of both conditions, clinicians can more fully assess their patients' clinical and nutritional status and can tailor targeted therapies to meet their needs and improve outcomes. This proposed syndrome embodies the inherent association of malnutrition and sarcopenia, highlighting their combined impact on clinical outcomes. The objective of this review paper is to characterize MalnutritionSarcopenia Syndrome to advance clinical practice, by providing clinicians with the necessary background information to integrate nutritional assessment along with loss of muscle mass and functionality in their everyday clinical practice.
\end{abstract}

\section{Introduction}

Historically, malnutrition has been defined as a condition of an imbalance of energy, protein, and other nutrients that cause measurable negative effects on body composition, physical function, and clinical outcomes [1]. Typical measures that clinicians use to screen and assess for malnutrition or the risk for malnutrition include dietary or nutrient intake, changes in body weight, and laboratory values [2]. A new definition of malnutrition has recently been proposed by an International Guideline Consensus Committee, integrating the acuity of the associated disease and inflammation [3]. The committee specified three subtypes of malnutrition using an etiology-based terminology to assist clinicians to make a nutrition diagnosis in clinical practice settings: (1) starvation-related without inflammation, (2) chronic disease or conditions that impose sustained mildto-moderate inflammation (e.g., sarcopenic obesity, organ failure, and pancreatic cancer), and (3) acute disease or injury states, when inflammatory response is marked [3].

One critical clinical aspect often not assessed in nutrition screening or assessment is lean body mass or muscle mass loss. Lean body mass (LBM) is defined as that portion of the body mass that is everything but fat and includes water, mineral, muscle, and other protein-rich structures (e.g., enzymes, viscera, red cells, and connective tissues) [4]. Skeletal muscle mass constitutes the majority of LBM and provides strength, mobility, and balance [5]. Muscle mass also plays a critical role in whole-body protein metabolism and impacts quality of life in patients with chronic diseases [6]. The balance between muscle protein anabolism and catabolism is vitally important to maintaining skeletal muscle mass, particularly in older adults who lose muscle mass as a consequence of aging and/or illness $[6,7]$. It was not until 1989, when Irwin Rosenberg introduced the term sarcopenia [8]. The European Working Group on Sarcopenia 
in Older People (EWGSOP) defines sarcopenia as an agerelated loss of muscle mass, combined with loss of strength, functionality, or both (Figure 1) [9]. The working group also proposed a diagnostic algorithm for sarcopenia that is based on the presence of low muscle mass plus either low muscle strength (e.g., low handgrip strength) or low physical performance (e.g., 4 meter walking speed).

Sarcopenia is further classified into either primary or secondary categories. Primary sarcopenia, when no specific etiologic cause can be identified, is progressive and associated with the impact of aging: a reduction in motor neurons, alterations in skeletal muscle tissue including mitochondrial dysfunction, changes in the hormonal milieu (e.g., insulin resistance and a reduction in insulin-like growth factor- 1 and an increase in proinflammatory cytokines, such as tumor necrosis factor $\alpha$ and interleukin 6 . Next to the intrinsic, age-related processes, a multitude of extrinsic and behavioral factors can aggravate the development and/or progression of sarcopenia, leading to secondary sarcopenia, such as disuse and lack of physical activity, malnutrition, chronic inflammation, and comorbidity. As such, sarcopenia can be thought of as both a process and an outcome. Sarcopenia as a condition is a major cause of frailty and disability in older adults; as an active process, it is present in every person reaching adult life [9].

\section{Malnutrition and Sarcopenia Are Prevalent among Older Adults}

There are no published data demonstrating the cooccurrence of malnutrition and sarcopenia in older adults. However, research has shown that reductions in handgrip strength are common in individuals who have sarcopenia as well as in individuals who are malnourished $[9,10]$. Many older adults are malnourished or at high risk for malnutrition due to many factors. Decreased appetite and food intake, poor dentition, an increased frequency and severity of acute and chronic medical conditions, multiple medications, social and economic challenges, and cognitive decline all play a role in the etiology of malnutrition among older adults. Advanced age is an independent risk factor for malnutrition and is associated with a lower body weight, body mass index (BMI), and serum albumin [11-13].

The prevalence of malnutrition is greater among older adults in health care settings than in the community (Table 1). In hospital settings, malnutrition among older patients is approximately $56 \%$ [11]. For older adults living in the community, the prevalence of malnutrition ranges from 1 to $10 \%$, while $41-48 \%$ are at risk for malnutrition [14]. Consistently, in a large international study, malnutrition was present in $2 \%$ of those living in the community, $9 \%$ of outpatients and home care combined, $23 \%$ in the hospital, $21 \%$ in institutions, and $15 \%$ in those with cognitive impairment [15].

Age-associated loss of muscle mass is characterized by a $3-8 \%$ decline per decade after the age of 30 years with further decline in adults 60 years of age and older $[7,16]$. With aging, the loss of muscle mass is accompanied by an increase in body fat [17]. On average, adults can experience annual losses of $0.23 \mathrm{~kg}$ of muscle and gains of $0.45 \mathrm{~kg}$ of fat between 30 and 60 years of age [18]. Acute illness and injury can accelerate age-related changes in body composition. Studies demonstrate that, following injury, patients can lose 5-6\% of their total body weight - most of which is muscle mass and gain between 4 and $11 \%$ in fat mass within 12 months, with the majority of LBM loss occurring within the first two to four months after the injury [19].

Using the EWGSOP diagnostic criteria, Landi et al. evaluated the baseline data of adults who were 80 years of age or older $(n=260)$ from the ilSIRENTE study. The results of the study indicated that sarcopenia is prevalent among community-dwelling older adults with no differences based on gender (25\%) [20]. Using the same diagnostic algorithm, Landi et al. demonstrated that the prevalence of sarcopenia is slightly higher (32.8\%) among older adults in long-term care settings and was higher among male residents $(68 \%)$ than among female residents (21\%) [21].

Reductions in muscle mass among older adults are common and can contribute to functional impairment, disability, increased risk for falls [20], lowered quality of life, and increased risk for mortality. For instance, using crosssectional body composition data from the Third National Health and Nutrition Examination Survey, Janssen and colleagues determined the prevalence of class I sarcopenia (skeletal muscle mass index within one to two standard deviations below sex-specific values for young adults) and class II sarcopenia (skeletal muscle mass index two standard deviations of young adult values) in adults age 50 years of older. Among adults 50 years of age and older, the prevalence of class I sarcopenia was estimated between 37 and $47 \%$ in men and $50-61 \%$ in women, and a prevalence of class II sarcopenia between $5-7 \%$ in men and $7-11 \%$ in women. The prevalence of sarcopenia increased from the third to sixth decades and remained constant among subjects 70 years of age and older, while the prevalence of class I (59\% versus $45 \%)$ and class II (10\% versus $7 \%)$ was greater in women $\geq 50$ years of age than men $(P<0.001)$. Moreover, functional impairment was 2-3-fold higher in older subjects with class II sarcopenia than those with normal muscle mass, even after adjusting for age, race, BMI, health behaviors, and comorbidities [22].

\section{Malnutrition Sarcopenia Syndrome and Clinical Outcomes}

In many patient populations, malnutrition and sarcopenia are present in parallel and manifest clinically through a combination of decreased nutrient intake, decreased body weight, along with a decrease in muscle mass, strength, and/or physical function. This leads us to coin the proposed clinical syndrome of Malnutrition-Sarcopenia Syndrome (MSS). MSS is the clinical presentation of both malnutrition and accelerated age-associated loss of lean body mass, strength, and/or physical performance. Malnutrition and sarcopenia are each independently associated with negative health consequences that impact older adults across health care 


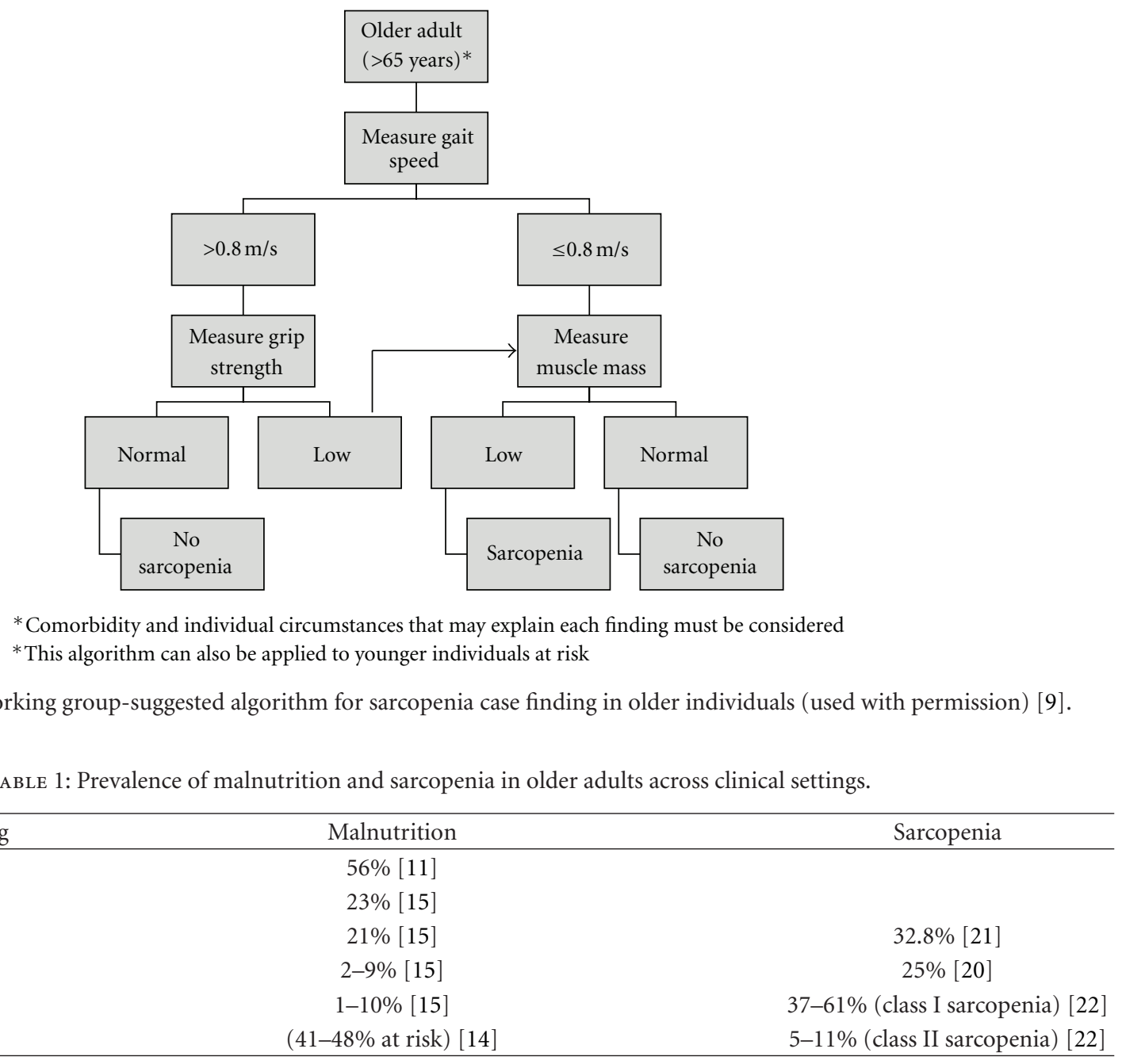

settings. Patients with malnutrition and/or sarcopenia are at risk of increased morbidity and mortality, decreased quality of life and functioning and increased rehospitalization, length of hospital stay, and healthcare costs. Importantly, malnutrition and sarcopenia are associated with increased mortality [23-27]. Cederholm et al. found significant differences in mortality rates between malnourished patients and well-nourished patients after hospitalization (44\% versus $18 \%$, respectively) [23]. In community-dwelling older adults, unintentional weight loss and low BMI are associated with elevated 3-year mortality rates, and older adults reporting unintentional weight loss were 1.67 times more likely to experience mortality than those who reported no weight loss [28]. Newman and colleagues demonstrated that 5\% weight loss over a three-year period is a significant and independent predictor of mortality in community-dwelling aging adults [17]. Similarly, Cereda et al. determined that low BMI predicted mortality in older institutionalized adults [29]. Interestingly, a prospective observational cohort of older adults demonstrated that higher lean mass and lean mass index predicted lower mortality with an $85 \%$ reduction in risk, suggesting that changes in lean mass and lean mass index, rather than BMI, are better predictors of mortality in older adults and highlighting the role of lean muscle mass loss in defining malnutrition [30]. Sarcopenia has also been linked with increased mortality in various patient populations. Recently, Landi et al. demonstrated that sarcopenia is highly prevalent in older nursing home residents and is associated with a significantly increased risk of allcause death [31]. Additionally, Bunout et al. evaluated the relationship between the loss of fat-free mass and mortality among aging adults $(n=1413,74.3 \pm 5.6$ years of age) and showed that low fat-free mass was significantly associated with mortality among individuals over 74 years of age [32]. Furthermore, results from a recent meta-analysis show that objective measures of physical capability, such as handgrip strength, walking speed, and chair rise, are predictors of allcause mortality in older community-dwelling populations [33]. The loss of function associated with sarcopenia and malnutrition is a risk factor for negative outcomes.

Malnutrition and sarcopenia are associated with increased morbidity, in particular increased infection and complications rates, including falls [34] and disability [35]. In a study of hospitalized patients, malnutrition was shown to be a significant independent risk factor for nosocomial infections, with infection rates of $4.4 \%$ in the 
well-nourished group, $7.6 \%$ in the moderate malnutrition group as compared to $14.6 \%$ in the severely malnourished group [36]. In addition, serum albumin levels, age, weight, immunodeficiency, and nutrition risk index score were associated with increased risk of nosocomial infections [36]. Edington et al. determined that malnourished patients experience a two-fold increase in rates of infection as compared to well-nourished patients, indicating that malnutrition is associated with hospital-acquired infections [37]. Similarly, a study of hospitalized older adults demonstrated that patients identified with sarcopenia (detected by dual energy X-ray absorptiometry (DXA)) upon admission were at a greater risk of contracting a nosocomial infection during the first 3 weeks of hospitalization (relative risk of 2.1) [38].

Malnutrition and loss of muscle mass compromise the quality of life and functional capacity of aging adults. Malnutrition is associated with declines in functional capacity in hospitalized patients [39]. Moreover, reduced quality of life has been reported among malnourished patients with a total Mini-Nutritional Assessment (MNA) score <24 [40]. Malnutrition significantly impacts the clinical outcomes of community-dwelling older adults. Specifically, older patients who are malnourished are more likely to be discharged to a residential home and less likely to return home [41, 42] with an increased length of convalescence, greater disability and dependence on walking devices, and loss of muscle strength after hospitalization [43-45]. Other consequences of sarcopenia are persistent sense of fatigue, muscle weakness, increased predisposition to metabolic disorders, and increased risk of falls and fractures [46]. Studies suggest that loss of muscle mass is a predictor of functional decline in independent older adults and those with disability [22, 47] and that age-related loss of muscle mass is directly correlated with loss in strength [48]. Interestingly, Reid et al. showed that lower extremity muscle mass is a strong independent predictor of the level of functional impairment [49]. Loss of strength with aging tends to track with loss of muscle mass in physiological studies although the decline in muscle strength is steeper than the decline in muscle mass [50]. Also, interventions that increase muscle mass do not necessarily increase strength, and changes in strength that occur with resistance training precede measurable changes in muscle mass. Correlations between change in muscle mass and change in strength in older adults are therefore not consistent. Recently, the term "sarcopenia with limited mobility" was proposed as a syndrome that occurs when sarcopenia leads to loss of function and individuals become candidates for therapeutic interventions [51].

In addition to increased risk of infections and functional impairment, malnutrition and loss of muscle mass are also associated with increased hospital length of stay (LOS) $[11,37,52-55]$. Moreover, studies have shown that weight loss and malnutrition are predictors of increased rehospitalization rates in adults [56-59]. In one study, LOS is significantly shorter among well-nourished patients (5.7 days) as compared to malnourished patients (8.9 days) [60]. Leandro-Merhi et al. reported that well-nourished patients are three times more likely to be discharged sooner than patients with varying degrees of malnutrition [55]. Additionally, severely malnourished patients with a BMI < $20 \mathrm{~kg} / \mathrm{m}^{2}$ or weight loss of greater than $10 \%$ stayed in the hospital even longer at 18.3 and 17.5 days, respectively [37]. Hospitalization is associated with significant reductions in muscle mass and strength and functional decline in older adults [44, 61-64]. Interestingly, in a large sample of patients, Pichard et al. determined that fat-free mass (FFM) and fatfree mass index are significantly lower among elderly hospitalized patients than their nonhospitalized counterparts. Additionally, $37 \%$ of patients hospitalized for just 1-2 days had low FFM, which increased to $55.6 \%$ after 12 days of hospitalization [65]. Another study concluded that shortterm hospitalization was associated with significant declines in functional capacity and muscle strength, regardless of age or baseline functional status [45]. The relationship between hospitalization-related loss of muscle mass and strength and declining functional capacity and the risk for future hospital admission needs further exploration.

Collectively, malnutrition, loss of muscle mass, strength, and functional capacity are accelerated in hospitalized older adults $[55,61,62,66]$. Increased LOS worsens malnutrition and sarcopenia, creating a vicious cycle of disease severity, increased frequency and severity of complications, increasing LOS, and rehospitalization rates [62].

Due to their associated comorbid conditions, malnutrition and sarcopenia impose a major economic burden on healthcare systems, contributing to escalating healthcare costs. A study of hospitalized patients showed significantly increased costs in malnourished patients. The mean daily expense was $\$ 228.00$ per malnourished patients versus $\$ 138.00$ per well-nourished patients, a cost increase of $60.5 \%$, after including costs for medications and tests, the cost to treat malnourished patients rose by $308.9 \%$ [53]. According to a British Association of Parenteral and Enteral Nutrition report, malnutrition in the UK costs in excess of $\mathfrak{E} 13$ billion per year: $\mathfrak{E} 8$ billion is for healthcare, including hospital inpatients and outpatients, and primary care (prescriptions

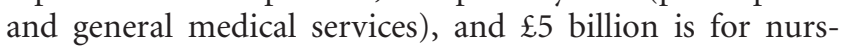
ing, residential, and home care services [67]. Additionally, sarcopenia significantly increases health care costs. A 2000 US study estimated that sarcopenia resulted in $\$ 18.5$ billion dollars in direct health care expenditures, which reflected $1.5 \%$ of total healthcare expenditures. Moreover, a $10 \%$ reduction in sarcopenia prevalence would result in $\$ 1.1$ billion US dollars in health care savings [68].

\section{Screening and Assessing for Malnutrition Sarcopenia Syndrome}

Clinicians should integrate nutrition assessment with sarcopenia screening for optimal evaluation of these two interrelated nutritional issues to help improve patients' clinical outcomes. A variety of malnutrition screening tools are available such as the Malnutrition Screening Tool (MST) [69], Malnutrition Universal Screening Tool (MUST) [70], the short form of the Mini-Nutritional Assessment (SF-MNA) [71] and Nutrition Risk Screening-2002 (NRS-2002) [72]. 
TABLE 2: The clinical signs and symptoms of MalnutritionSarcopenia Syndrome.

\begin{tabular}{lc}
\hline & Malnutrition-Sarcopenia Syndrome \\
Malnutrition & Sarcopenia \\
\hline$\downarrow$ Food intake & $\downarrow$ Muscle mass \\
$\downarrow$ Appetite & $\downarrow$ Muscle strength and/or functionality \\
$\downarrow$ Body weight & \\
\hline
\end{tabular}

A standard for nutritional assessment, the Subjective Global Assessment (SGA), is a valid and reliable method to assess nutritional status in a variety of patient populations [73]. The MNA is another reliable assessment tool validated for use with older adults in multiple settings [71, 74]. Elements of history and physical examination are commonly shared among these tools and include unintentional weight loss (e.g., $3 \mathrm{~kg}$ within the last 3 months), decreased food intake, gastrointestinal symptoms, and functional impairment. For sarcopenia screening, a simple clinician tool has been suggested by the European Geriatric Medical Society (EUGMS) Consensus Committee of defining sarcopenia (Figure 1), in which older adults are screened and assessed for sarcopenia using both gait speed and handgrip strength measurements $[9,75-77]$. If a patient is identified to have slow gait speed or low hand grip strength, muscle mass should then be measured and evaluated. Based on the evidence presented, the combination of screening and assessing for malnutrition and sarcopenia is recommended to screen for the presence of MSS in at-risk patient populations, particularly older adults in clinical settings and in the community. The proposed clinical signs and symptoms to identify MSS are highlighted in Table 2. Specifically, to facilitate screening and assessment of MSS, we propose that patients would be at high risk for MSS if at least four of these criteria are present:

(1) recent history of reduced appetite that resulted in poor food intake,

(2) unintentional weight loss of $3 \mathrm{~kg}$ or more over the last 3 months,

(3) low muscle mass (as measured by DXA, CT, MRI, or BIA),

(4) decreased gait speed (less than 0.8 meter/second), and

(5) reduced hand grip strength for age and gender.

Future research is warranted to determine the reliability and validity of this assessment tool across patient populations and settings.

\section{Conclusion}

Malnutrition and sarcopenia are both commonly occurring conditions across patient populations, especially older adults. Both conditions result in numerous and substantial negative outcomes to both the patient and the health care system, including increased morbidity and mortality, decreased patient quality of life and functionality, and increased health care costs and rehospitalization rates. Historically, patients have been screened or assessed by healthcare practitioners for either malnutrition or sarcopenia, but rarely for both conditions concurrently. However, many patients present clinically with both conditions in parallel and this combination, or the malnutrition sarcopenia syndrome should be the focus of future nutrition screening and assessment in at-risk patient populations. Examining the entirety of the patient's nutritional and functional status through screening and assessment for both malnutrition and sarcopenia will enable healthcare practitioners to better determine the presence of MSS in their patients and target interventions to fit the patients' needs. Moreover, as the world is aging and older adults will utilize health care services at an increased rate, this could ultimately result in better patient care and outcomes in this unique and expanding patient population. Clinicians and researchers are called upon to work together to develop a practical, reliable, and valid tool for MSS that is appropriate for implementation into a variety of clinical practice settings, with the aim of identifying patients with MSS and providing the appropriately targeted interventions.

\section{Acknowledgments}

MFJV is a professor of geriatric medicine and a paid speaker and consultant to Abbott Nutrition. C. J. Alish, A. C. Sauer, and R. A. Hegazi are employees of Abbott Nutrition, Abbott Laboratories. The material presented in this paper is based on published clinical evidence and is not affected by any financial relationship.

\section{References}

[1] M. Elia and Malnutrition Advisory Group, Guidelines for Detection and Management of Malnutrition, BAPEN, Maidenhead, UK, 2000.

[2] R. J. Stratton, C. J. Green, and M. Elia, Disease-Related Malnutrition: An Evidence-Based Approach to Treatment, CABI, Wallingford, UK, 2003.

[3] G. L. Jensen, J. Mirtallo, C. Compher et al., "Adult starvation and disease-related malnutrition: a proposal for etiologybased diagnosis in the clinical practice setting from the International Consensus Guideline Committee," Clinical Nutrition, vol. 29, no. 2, pp. 151-153, 2010.

[4] R. H. Demling, "Nutrition, anabolism, and the wound healing process: an overview," ePlasty, vol. 9, pp. 65-94, 2009.

[5] R. R. Wolfe, "The underappreciated role of muscle in health and disease," American Journal of Clinical Nutrition, vol. 84, no. 3, pp. 475-482, 2006.

[6] J. J. McCarthy and K. A. Esser, "Anabolic and catabolic pathways regulating skeletal muscle mass," Current Opinion in Clinical Nutrition and Metabolic Care, vol. 13, no. 3, pp. 230235, 2010.

[7] K. S. Nair, "Muscle protein turnover: methodological issues and the effect of aging," Journals of Gerontology A, vol. 50, pp. 107-112, 1995.

[8] I. H. Rosenberg, "Sarcopenia: origins and clinical relevance," Journal of Nutrition, vol. 127, no. 5, supplement, pp. 990S991S, 1997.

[9] A. J. Cruz-Jentoft, J. P. Baeyens, J. M. Bauer et al., "Sarcopenia: European consensus on definition and diagnosis," Age and Ageing, vol. 39, no. 4, pp. 412-423, 2010. 
[10] K. Norman, N. Stobäus, M. C. Gonzalez, J. D. Schulzke, and M. Pirlich, "Hand grip strength: outcome predictor and marker of nutritional status," Clinical Nutrition, vol. 30, no. 2, pp. 135142, 2011.

[11] M. Pirlich, T. Schütz, K. Norman et al., "The German hospital malnutrition study," Clinical Nutrition, vol. 25, no. 4, pp. 563572, 2006.

[12] M. Pirlich, T. Schütz, M. Kemps et al., "Social risk factors for hospital malnutrition," Nutrition, vol. 21, no. 3, pp. 295-300, 2005.

[13] S. Forster and S. Gariballa, "Age as a determinant of nutritional status: a cross sectional study," Nutrition Journal, vol. 4, article 28, 2005.

[14] L. C. P. G. M. de Groot, A. M. Beck, M. Schroll, and W. A. van Staveren, "Evaluating the DETERMINE your nutritional health checklist and the mini nutritional assessment as tools to identify nutritional problems in elderly Europeans," European Journal of Clinical Nutrition, vol. 52, no. 12, pp. 877-883, 1998.

[15] Y. Guigoz, "The Mini Nutritional Aseesment (MNA) review of the literature-what does it tell us?" The Journal of Nutrition, Health \& Aging, vol. 10, no. 6, pp. 466-487, 2006.

[16] D. Paddon-Jones, Lean Body Mass Loss With Age, Abbott Nutrition, Columbus, Ohio, USA, 2009, Edited by: J. Gussler.

[17] A. B. Newman, J. S. Lee, M. Visser et al., "Weight change and the conservation of lean mass in old age: The Health, Aging and Body Composition Study," American Journal of Clinical Nutrition, vol. 82, no. 4, pp. 872-878, 2005.

[18] G. B. Forbes, "Longitudinal changes in adult fat-free mass: influence of body weight," American Journal of Clinical Nutrition, vol. 70, no. 6, pp. 1025-1031, 1999.

[19] M. Karlsson, J. Å. Nilsson, I. Sernbo, I. Redlund-Johnell, O. Johnell, and K. J. Obrant, "Changes of bone mineral mass and soft tissue composition after hip fracture," Bone, vol. 18, no. 1, pp. 19-22, 1996.

[20] F. Landi, R. Liperoti, A. Russo et al., "Sarcopenia as a risk factor for falls in elderly individuals: results from the ilSIRENTE study," Clinical Nutrition. In press.

[21] F. Landi, R. Liperoti, D. Fusco et al., "Prevalence and risk factors of sarcopenia among nursing home older residents," Journals of Gerontology A, vol. 67, pp. 48-55, 2012.

[22] I. Janssen, S. B. Heymsfield, and R. Ross, "Low relative skeletal muscle mass (sarcopenia) in older persons is associated with functional impairment and physical disability," Journal of the American Geriatrics Society, vol. 50, no. 5, pp. 889-896, 2002.

[23] T. Cederholm, C. Jagren, and K. Hellstrom, "Outcome of protein-energy malnutrition in elderly medical patients," American Journal of Medicine, vol. 98, no. 1, pp. 67-74, 1995.

[24] A. B. Newman, D. Yanez, T. Harris, A. Duxbury, P. L. Enright, and L. P. Fried, "Weight change in old age and its association with mortality," Journal of the American Geriatrics Society, vol. 49, no. 10, pp. 1309-1318, 2001.

[25] J. I. Wallace, R. S. Schwartz, A. Z. LaCroix, R. F. Uhlmann, and R. A. Pearlman, "Involuntary weight loss in older outpatients: incidence and clinical significance," Journal of the American Geriatrics Society, vol. 43, no. 4, pp. 329-337, 1995.

[26] D. F. Williamson and E. R. Pamuk, "The association between weight loss and increased longevity: a review of the evidence," Annals of Internal Medicine, vol. 119, no. 7, pp. 731-736, 1993.

[27] S. A. French, A. R. Folsom, R. W. Jeffery, and D. F. Williamson, "Prospective study of intentionality of weight loss and mortality in older women: The Iowa Women's Health Study,"
American Journal of Epidemiology, vol. 149, no. 6, pp. 504-514, 1999.

[28] J. L. Locher, D. L. Roth, C. S. Ritchie et al., "Body mass index, weight loss, and mortality in community-dwelling older adults," Journals of Gerontology A, vol. 62, no. 12, pp. 1389-1392, 2007.

[29] E. Cereda, C. Pedrolli, A. Zagami et al., "Body mass index and mortality in institutionalized elderly," Journal of the American Medical Directors Association, vol. 12, no. 3, pp. 174-178, 2011.

[30] S. S. Han, K. W. Kim, K. I. Kim et al., "Lean mass index: a better predictor of mortality than body mass index in elderly Asians," Journal of the American Geriatrics Society, vol. 58, no. 2, pp. 312-317, 2010.

[31] F. Landi, R. Liperoti, D. Fusco et al., "Sarcopenia and mortality among older nursing home residents," Journal of the American Medical Directors Association, vol. 13, no. 2, pp. 121-126, 2011.

[32] D. Bunout, M. P. de la Maza, G. Barrera, L. Leiva, and S. Hirsch, "Association between sarcopenia and mortality in healthy older people," Australasian Journal on Ageing, vol. 30, no. 2, pp. 89-92, 2011.

[33] R. Cooper, D. Kuh, and R. Hardy, "Objectively measured physical capability levels and mortality: systematic review and meta-analysis," British Medical Journal, vol. 341, Article ID c4467, 2010.

[34] E. M. Castillo, D. Goodman-Gruen, D. Kritz-Silverstein, D. J. Morton, D. L. Wingard, and E. Barrett-Connor, "Sarcopenia in elderly men and women: The Rancho Bernardo Study," American Journal of Preventive Medicine, vol. 25, no. 3, pp. 226-231, 2003.

[35] I. Janssen, "Influence of sarcopenia on the development of physical disability: The Cardiovascular Health Study," Journal of the American Geriatrics Society, vol. 54, no. 1, pp. 56-62, 2006.

[36] S. M. Schneider, P. Veyres, X. Pivot et al., "Malnutrition is an independent factor associated with nosocomial infections," British Journal of Nutrition, vol. 92, no. 1, pp. 105-111, 2004.

[37] J. Edington, J. Boorman, E. R. Durrant et al., "Prevalence of malnutrition on admission to four hospitals in England," Clinical Nutrition, vol. 19, no. 3, pp. 191-195, 2000.

[38] G. Cosquëric, A. Sebag, C. Ducolombier, C. Thomas, F. Piette, and S. Weill-Engerer, "Sarcopenia is predictive of nosocomial infection in care of the elderly," British Journal of Nutrition, vol. 96, no. 5, pp. 895-901, 2006.

[39] A. Vivanti, N. Ward, and T. Haines, "Nutritional status and associations with falls, balance, mobility and functionality during hospital admission," The Journal of Nutrition, Health \& Aging, vol. 15, no. 5, pp. 388-391, 2011.

[40] S. A. Neumann, M. D. Miller, L. Daniels, and M. Crotty, "Nutritional status and clinical outcomes of older patients in rehabilitation," Journal of Human Nutrition and Dietetics, vol. 18, no. 2, pp. 129-136, 2005.

[41] J. Potter, K. Klipstein, J. J. Reilly, and M. Roberts, "The nutritional status and clinical course of acute admissions to a geriatric unit," Age and Ageing, vol. 24, no. 2, pp. 131-136, 1995.

[42] R. Muhlethaler, A. E. Stuck, C. E. Minder, and B. M. Frey, "The prognostic significance of protein-energy malnutrition in geriatric patients," Age and Ageing, vol. 24, no. 3, pp. 193197, 1995.

[43] M. Lumbers, L. T. Driver, R. J. Howland, M. W. J. Older, and C. M. Williams, "Nutritional status and clinical outcome 
in elderly female surgical orthopaedic patients," Clinical Nutrition, vol. 15, no. 3, pp. 101-107, 1996.

[44] T. M. Gill, H. G. Allore, T. R. Holford, and Z. Guo, "Hospitalization, restricted activity, and the development of disability among older persons," Journal of the American Medical Association, vol. 292, no. 17, pp. 2115-2124, 2004.

[45] M. M. Suesada, M. A. Martins, and C. R. Carvalho, "Effect of short-term hospitalization on functional capacity in patients not restricted to bed," American Journal of Physical Medicine and Rehabilitation, vol. 86, no. 6, pp. 455-462, 2007.

[46] T. Lang, T. Streeper, P. Cawthon, K. Baldwin, D. R. Taaffe, and T. B. Harris, "Sarcopenia: etiology, clinical consequences, intervention, and assessment," Osteoporosis International, vol. 21, no. 4, pp. 543-559, 2010.

[47] M. Visser, B. H. Goodpaster, S. B. Kritchevsky et al., "Muscle mass, muscle strength, and muscle fat infiltration as predictors of incident mobility limitations in well-functioning older persons," Journals of Gerontology A, vol. 60, no. 3, pp. 324-333, 2005.

[48] W. J. Evans, "Effects of exercise on body composition and functional capacity of the elderly," Journals of Gerontology A, vol. 50, pp. 147-150, 1995.

[49] K. F. Reid, E. N. Naumova, R. J. Carabello, E. M. Phillips, and R. A. Fielding, "Lower extremity muscle mass predicts functional performance in mobility-limited elders," The Journal of Nutrition, Health \& Aging, vol. 12, no. 7, pp. 493-498, 2008.

[50] W. R. Frontera, D. Suh, L. S. Krivickas, V. A. Hughes, R. Goldstein, and R. Roubenoff, "Skeletal muscle fiber quality in older men and women," American Journal of Physiology, vol. 279, no. 3, pp. C611-C618, 2000.

[51] J. E. Morley, A. M. Abbatecola, J. M. Argiles et al., "Sarcopenia with limited mobility: an international consensus," Journal of the American Medical Directors Association, vol. 12, pp. 403409, 2011.

[52] J. Dzieniszewski, M. Jarosz, B. Szczygieł et al., "Nutritional status of patients hospitalised in Poland," European Journal of Clinical Nutrition, vol. 59, no. 4, pp. 552-560, 2005.

[53] M. I. Correia and D. L. Waitzberg, "The impact of malnutrition on morbidity, mortality, length of hospital stay and costs evaluated through a multivariate model analysis," Clinical Nutrition, vol. 22, no. 3, pp. 235-239, 2003.

[54] M. Suominen, S. Muurinen, P. Routasalo et al., "Malnutrition and associated factors among aged residents in all nursing homes in Helsinki," European Journal of Clinical Nutrition, vol. 59, no. 4, pp. 578-583, 2005.

[55] V. A. Leandro-Merhi, J. L. de Aquino, and J. F. Sales Chagas, "Nutrition status and risk factors associated with length of hospital stay for surgical patients," Journal of Parenteral and Enteral Nutrition, vol. 35, no. 2, pp. 241-248, 2011.

[56] C. S. Chima, K. Barco, M. L. Dewitt, M. Maeda, J. C. Teran, and K. D. Mullen, "Relationship of nutritional status to length of stay, hospital costs, and discharge status of patients hospitalized in the medicine service," Journal of the American Dietetic Association, vol. 97, no. 9, pp. 975-978, 1997.

[57] D. H. Sullivan and R. C. Walls, "Protein-energy undernutrition and the risk of mortality within six years of hospital discharge," Journal of the American College of Nutrition, vol. 17, no. 6, pp. 571-578, 1998.

[58] N. Allaudeen, A. Vidyarthi, J. Maselli, and A. Auerbach, "Redefining readmission risk factors for general medicine patients," Journal of Hospital Medicine, vol. 6, no. 2, pp. 54-60, 2011.
[59] A. M. Mudge, K. Kasper, A. Clair et al., "Recurrent readmissions in medical patients: a prospective study," Journal of Hospital Medicine, vol. 6, no. 2, pp. 61-67, 2011.

[60] J. Edington, J. Boorman, E. R. Durrant et al., "Prevalence of malnutrition on admission to four hospitals in England," Clinical Nutrition, vol. 19, no. 3, pp. 191-195, 2000.

[61] P. M. Cawthon, K. M. Fox, S. R. Gandra et al., "Do muscle mass, muscle density, strength, and physical function similarly influence risk of hospitalization in older adults?" Journal of the American Geriatrics Society, vol. 57, no. 8, pp. 1411-1419, 2009.

[62] D. E. Alley, A. Koster, D. MacKey et al., "Hospitalization and change in body composition and strength in a populationbased cohort of older persons," Journal of the American Geriatrics Society, vol. 58, no. 11, pp. 2085-2091, 2010.

[63] L. Ferrucci, J. M. Guralnik, M. Pahor, M. C. Corti, and R. J. Havlik, "Hospital diagnoses, medicare charges, and nursing home admissions in the year when older persons become severely disabled," Journal of the American Medical Association, vol. 277, no. 9, pp. 728-734, 1997.

[64] M. A. Sager, T. Franke, S. K. Inouye et al., "Functional outcomes of acute medical illness and hospitalization in older persons," Archives of Internal Medicine, vol. 156, no. 6, pp. 645652, 1996.

[65] C. Pichard, U. G. Kyle, A. Morabia, A. Perrier, B. Vermeulen, and P. Unger, "Nutritional assessment: lean body mass depletion at hospital admission is associated with an increased length of stay," American Journal of Clinical Nutrition, vol. 79, no. 4, pp. 613-618, 2004.

[66] P. Kortebein, A. Ferrando, J. Lombeida, R. Wolfe, and W. J. Evans, "Effect of 10 days of bed rest on skeletal muscle in healthy older adults," Journal of the American Medical Association, vol. 297, no. 16, pp. 1772-1774, 2007.

[67] M. Elia and C. A. Russell, "Combating malnutrition: recommendations for action. Report From the Advisory Group on Malnutrition," Led By BAPEN; Output of a meeting of the Advisory Group on Malnutrition, 12 June 2008.

[68] I. Janssen, D. S. Shepard, P. T. Katzmarzyk, and R. Roubenoff, "The healthcare costs of sarcopenia in the United States," Journal of the American Geriatrics Society, vol. 52, no. 1, pp. 80-85, 2004.

[69] M. Ferguson, S. Capra, J. Bauer, and M. Banks, "Development of a valid and reliable malnutrition screening tool for adult acute hospital patients," Nutrition, vol. 15, no. 6, pp. 458-464, 1999.

[70] M. Elia, Screening for Malnutrition: A Multidisciplinary Responsibility. Development and Use of the 'Malnutrition Universal Screening Tool' ('MUST') for Adults, BAPEN, Worcestershire, UK, 2003.

[71] Y. Guigoz, S. Lauque, and B. J. Vellas, "Identifying the elderly at risk for malnutrition the mini nutritional assessment," Clinics in Geriatric Medicine, vol. 18, no. 4, pp. 737-757, 2002.

[72] J. Kondrup, H. H. Ramussen, O. Hamberg et al., "Nutritional risk screening (NRS 2002): a new method based on an analysis of controlled clinical trials," Clinical Nutrition, vol. 22, no. 3, pp. 321-336, 2003.

[73] H. M. Kruizenga, M. W. Van Tulder, J. C. Seidell, A. Thijs, H. J. Ader, and M. A. van Bokhorst-de van der Schueren, "Effectiveness and cost-effectiveness of early screening and treatment of malnourished patients," American Journal of Clinical Nutrition, vol. 82, no. 5, pp. 1082-1089, 2005. 
[74] M. J. Kaiser, J. M. Bauer, C. Rämsch et al., "Frequency of malnutrition in older adults: a multinational perspective using the mini nutritional assessment," Journal of the American Geriatrics Society, vol. 58, no. 9, pp. 1734-1738, 2010.

[75] D. M. Buchner, E. B. Larson, E. H. Wagner, T. D. Koepsell, and B. J. de Lateur, "Evidence for a non-linear relationship between leg strength and gait speed," Age and Ageing, vol. 25, no. 5, pp. 386-391, 1996.

[76] H. C. Roberts, H. J. Denison, H. J. Martin et al., "A review of the measurement of grip strength in clinical and epidemiological studies: towards a standardised approach," Age and Ageing, vol. 40, no. 4, pp. 423-429, 2011.

[77] A. J. Cruz-Jentoft, F. Landi, E. Topinková, and J. P. Michel, "Understanding sarcopenia as a geriatric syndrome," Current Opinion in Clinical Nutrition and Metabolic Care, vol. 13, no. 1, pp. 1-7, 2010 . 


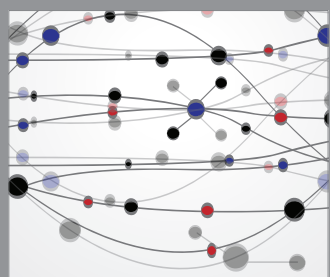

The Scientific World Journal
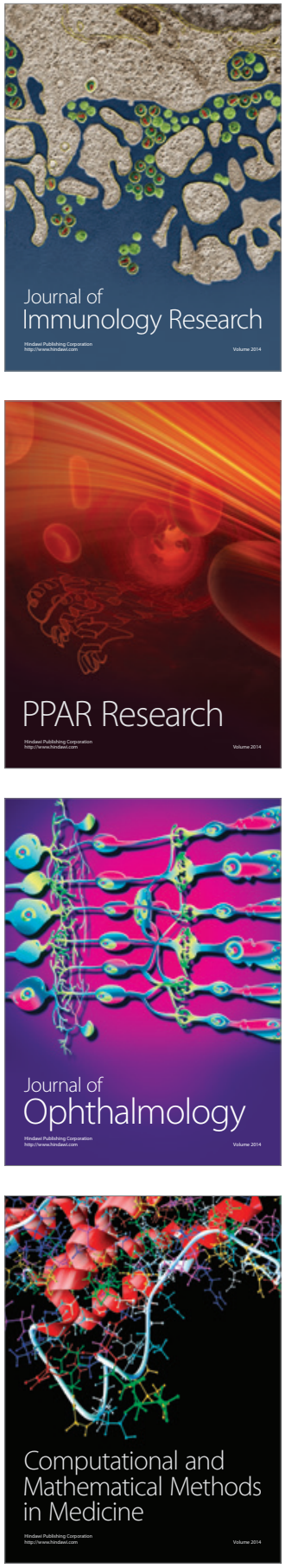

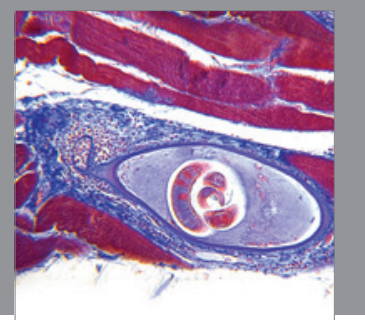

Gastroenterology

Research and Practice
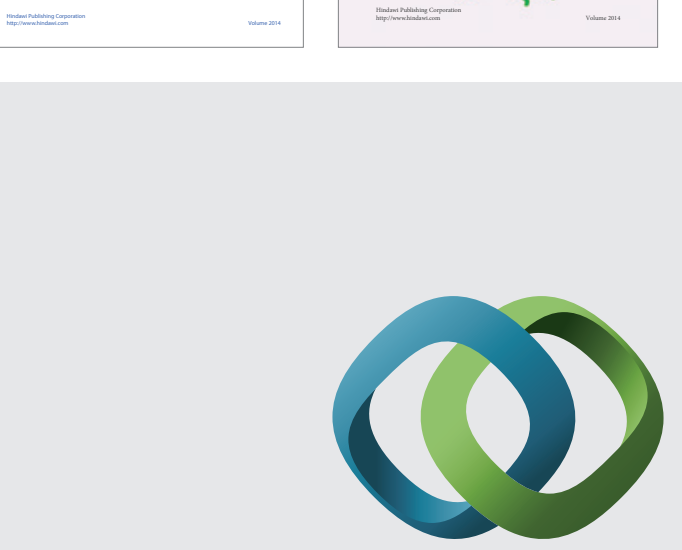

\section{Hindawi}

Submit your manuscripts at

http://www.hindawi.com
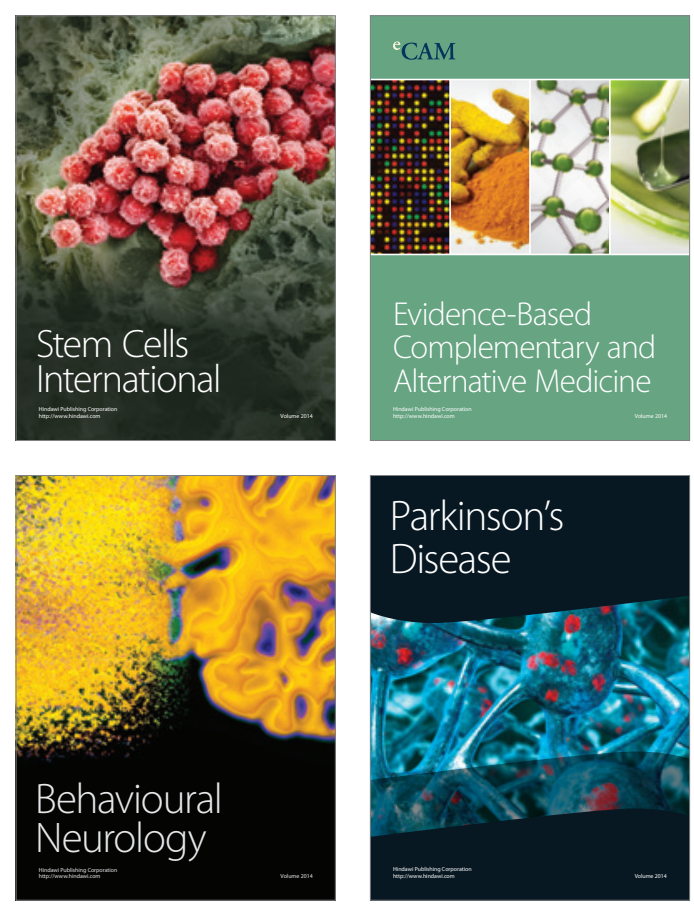

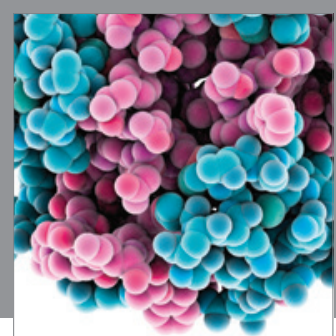

Journal of
Diabetes Research

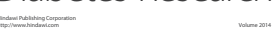

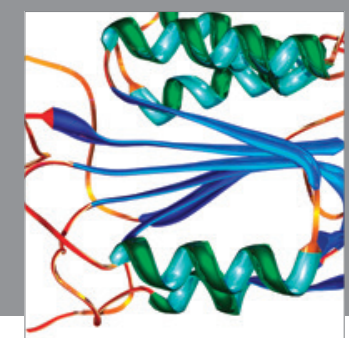

Disease Markers
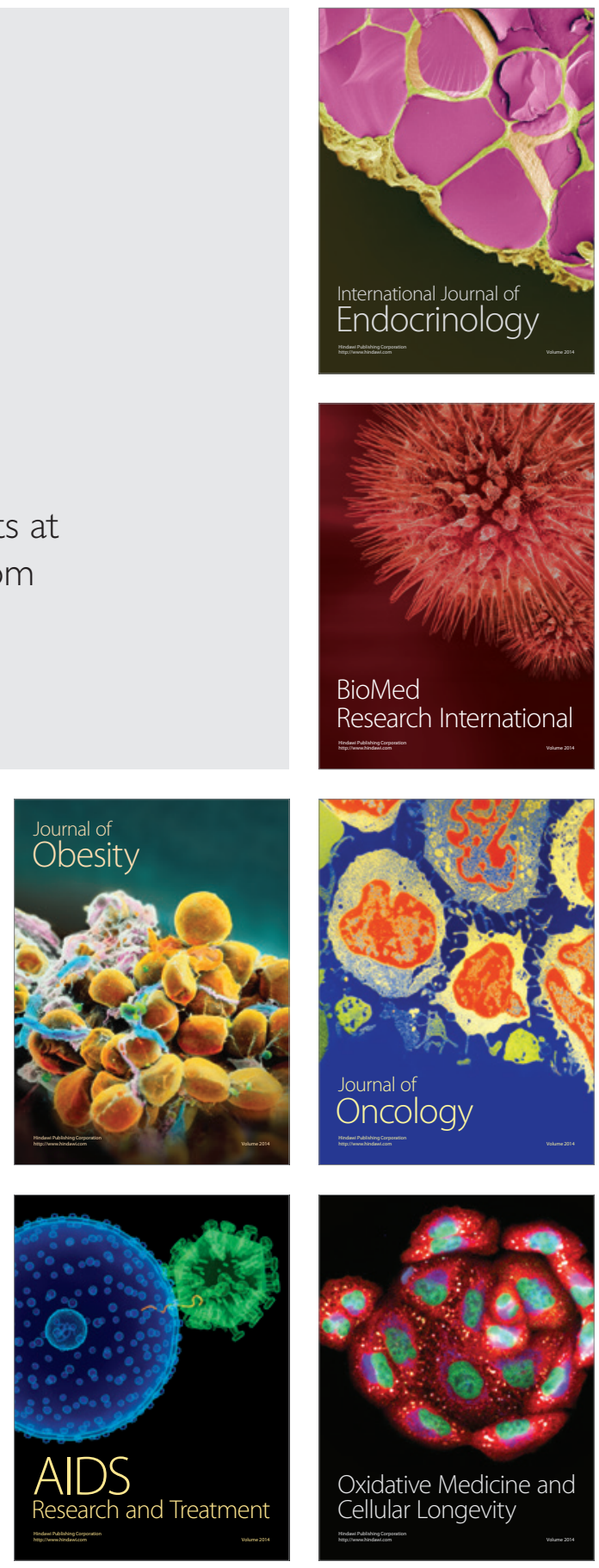